\title{
DINÂMICA DA PLANÍCIE COSTEIRA NOS LIMITES DA PRAIA DE ATALAIA NOVA, BARRA DOS COQUEIROS/SE
}

\author{
Lucas Silva Leite $^{(\mathrm{a})}$, Neise Mare de Souza Alves ${ }^{(\mathrm{b})}$ \\ (a) Departamento de Geografia, Universidade Federal de Sergipe, silwa_lukas@ hotmail.com \\ (b) Departamento de Geografia, Universidade Federal de Sergipe, neisemare @ gmail.com
}

Eixo: DINÂMICA E GESTÃO DE ZONAS COSTEIRAS

\begin{abstract}
Resumo
Os ambientes costeiros são dinâmicos e estão submetidos à atuação de processos de diferentes origens, naturais e antrópicos. A interferência humana costuma desencadear alterações no sistema ambiental. O objetivo deste trabalho é analisar a dinâmica da Planície Costeira nos limites da praia de Atalaia Nova, com base nos princípios sistêmicos que permitem a análise integrada da paisagem. Para isso, foram utilizados os seguintes materiais e procedimentos: pesquisa bibliográfica, fotointerpretação de aerofotos e imagens de satélite, análise e confeçção de mapas temáticos e trabalhos de campo. Os estudos realizados revelaram que os processos oceanográficos, fluviais e eólicos atuantes na Planície Costeira resultaram na elaboração de terraços marinhos, cordões litorâneos e dunas frontais, no setor de abrangência da praia. Entretanto, os tipos de uso e intervenções - construção de molhe na desembocadura do rio Sergipe, extração de areia e a especulação imobiliária - vêm concorrendo para a alteração dessas morfologias, descaracterizando a paisagem.
\end{abstract}

Palavras chave: Praia de Atalaia Nova. Planície Costeira. Processos costeiros. Paisagem.

\section{Introdução}

Os ambientes costeiros são dinâmicos e estão sob a atuação constante de processos eólicos, oceanográficos e fluviais. A interferência humana nesses ambientes desencadeia alterações na dinâmica dos componentes naturais que integram esse sistema ambiental.

Com frequência, na praia de Atalaia Nova, a interação dos condicionantes naturais e antrópicos têm proporcionado o surgimento ou modificação das morfologias existentes na faixa praial, revelando sinais de descaracterização da paisagem na margem esquerda da foz do rio Sergipe. No entanto, levando-se em consideração a concepção sistêmica, é possível afirmar que as consequências dessa interação se repercutem não apenas sobre os componentes biofísicos da paisagem, mas também na organização do uso e ocupação desse espaço pelos grupos sociais.

O presente estudo tem por objetivo analisar a dinâmica da Planície Costeira nos limites da praia de Atalaia Nova, segundo os princípios sistêmicos que permitem a análise integrada da paisagem. Desse modo, serão 
enfatizadas as interferências antrópicas sobre os elementos naturais, e as repercussões sobre a morfodinâmica e o modelado atual.

\section{Materiais e Métodos}

A realização dos estudos sobre a dinâmica da Planície Costeira nos limites da praia de Atalaia Nova apoiou-se na análise sistêmica, que permite a compreensão da paisagem de modo integrado (BERTRAND, 2004). Desse modo, essa abordagem se apresenta como adequada ao estudo proposto, diante das interações da dinâmica costeira dominante com as ações antropogênicas.

Para proceder à execução do estudo proposto, foram utilizados os seguintes materiais e procedimentos metodológicos: pesquisa bibliográfica; fotointerpretação de aerofotos e imagens de satélite; levantamento e análise dos documentos cartográficos; trabalhos de campo e confecção de mapas.

A pesquisa bibliográfica foi realizada junto aos acervos virtuais de instituições, bibliotecas de Universidades e órgãos públicos.

Para a fotointerpretação foram utilizadas as fotografias aéreas dos seguintes anos - 1965, escala 1:60.000, Serviço Aerofotogramétrico Cruzeiro do Sul (SACS); 1971, escala 1:70.000, TERRAFOTO; e 1984, escala 1: 25.000, Força Aérea Brasileira (FAB)/Secretaria de Estado do Planejamento de Sergipe (SEPLANTEC).

Foram analisadas também imagens de satélite da área de estudo, disponibilizadas pelo Google Earth Pro@, referentes a janeiro de 2004, dezembro de 2009, novembro de 2011 e janeiro de 2017. Em cada imagem foi traçada a posição ocupada pela linha de costa e o molhe. O indicador escolhido para a vetorização da linha de costa foi o limite da maré alta. Na demarcação do molhe foi considerado o alinhamento de blocos rochosos dispostos no limite da margem esquerda do rio Sergipe e o povoado de Atalaia Nova. Posteriormente, o produto desta vetorização, foi exportado para o software QGIS 2.18, onde foram sobrepostos, com a finalidade de obter uma síntese da evolução da linha de costa no período de 2004 a 2017.

Foram consultados e analisados os seguintes produtos cartográficos: os mapas temáticos do Projeto RADAMBRASIL (BRASIL, 1983), escala 1:1.000.000; o mapa e texto do Mapa Geológico do Estado de Sergipe, escala 1:250.000 (SANTOS et al., 1998); e os mapas temáticos dos Municípios Costeiros do Litoral Norte do estado de Sergipe, escala 1:100.000, elaborados por Alves (2010) . Para a confecção do mapa de localização de Barra dos Coqueiros, foram utilizados os shapes obtidos no banco de dados (GEOBANK) disponibilizado no site da Companhia de Pesquisa de Recursos Minerais (CPRM), organizados a partir do software QGIS 2.18. 


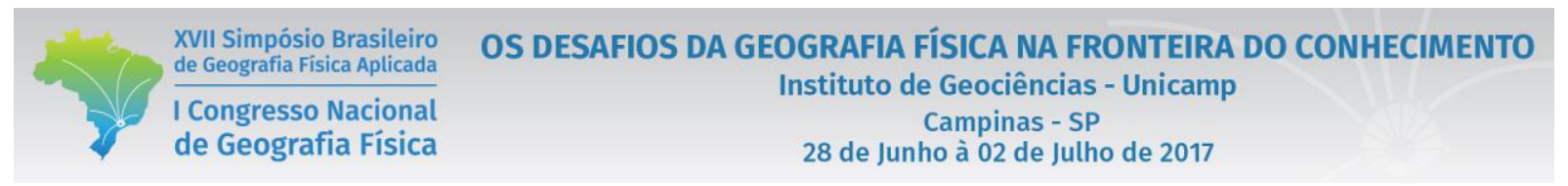

Os trabalhos de campo permitiram a observação da organização da paisagem, das condições de uso e ocupação da Planície Costeira, da dinâmica dos processos atuantes, e contato com moradores locais favorecendo o conhecimento de detalhes sobre a delimitação das praias, do quadro ambiental e socioeconômico da área num passado recente. Durante as visitas foram feitos registros fotográficos.

\section{Caracterização Geoambiental da área de estudo}

O estado de Sergipe possui um litoral com $163 \mathrm{~km}$ aproximadamente, subdividido em três setores - Norte, Centro e Sul (SANTOS, VILLAR, 2014). Barra dos Coqueiros está situado no litoral Norte, com extensão territorial de cerca de $90 \mathrm{~km}^{2}$, integrando a Grande Aracaju (IBGE, 2016). Segundo o censo realizado pelo IBGE, em 2010 a população municipal era de 24.976 habitantes com estimativa de 29.248 para 2016.

Os principais acessos ao município são a ponte Construtor João Alves, vetor de ligação com a capital Aracaju, e a Rodovia Estadual SE-100, que o conecta com os demais municípios do litoral Norte. Além dessas possibilidades, há ainda a rodovia SE-240, que permite o acesso ao município de Santo Amaro das Brotas e à Rodovia Federal BR-101. Barra dos Coqueiros limita-se ao Norte com Santo Amaro das Brotas e a Nordeste com Pirambu, estando separados, respectivamente, pelos rios Pomonga e Japaratuba; a Sudoeste faz divisa com a capital do estado, Aracaju, delimitados pelo rio Sergipe; e ao Sul e Leste com o Oceano Atlântico, segmento que abrange desde a foz do rio Sergipe até a foz do rio Japaratuba (Figura 1).

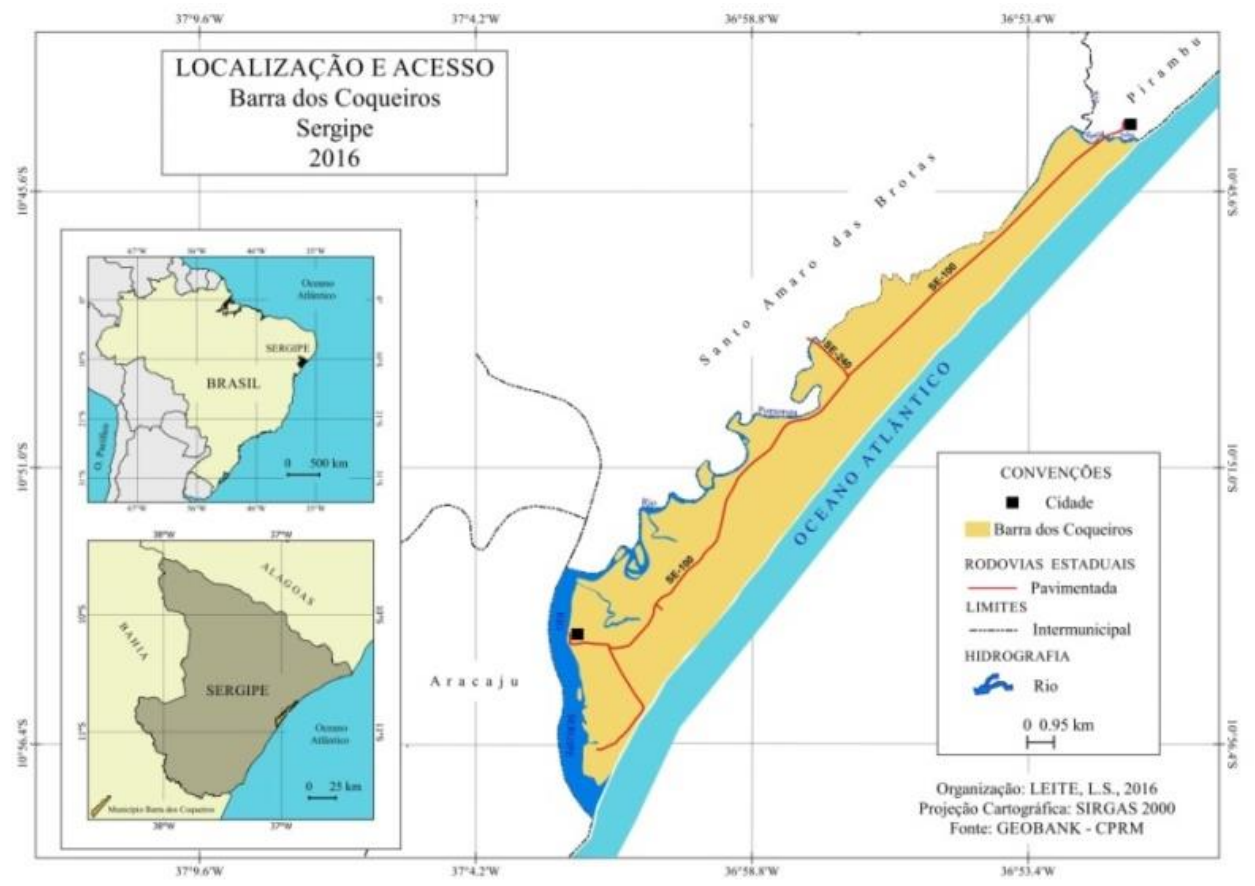

Figura 1 - Mapa de Localização e Acesso ao Município de Barra dos Coqueiros/SE 
XVII Simpósio Brasileiro

de Geografia Fisica Aplicada

I Congresso Nacional

de Geografia Física
OS DESAFIOS DA GEOGRAFIA FÍSICA NA FRONTEIRA DO CONHECIMENTO

Instituto de Geociências - Unicamp

Campinas - SP

28 de Junho à 02 de Julho de 2017

Atualmente, o município possui os seguintes povoados - Atalaia Nova, Olhos D'Água, Canal de São

Sebastião, Touro, Jatobá, Capuã e Pontal da Ilha (MENDONÇA, SILVA, 2009). Em Barra dos Coqueiros, por apresentar um litoral retilíneo e sem barreiras físicas naturais, a setorização da costa é estabelecida pela população local segundo critérios subjetivos, que identifica as seguintes praias - Praia de Atalaia Nova, Praia da Costa, Praia do Porto e Praia de Jatobá.

A praia de Atalaia Nova está situada no povoado homônimo, localizado no extremo sul de Barra dos Coqueiros, à margem esquerda da foz do rio Sergipe. Na atualidade, a praia supracitada tem limite no molhe da margem esquerda da desembocadura do rio Sergipe e se estende por aproximadamente $1.500 \mathrm{~m}$ (Figura 2), cuja paisagem é composta por diferentes elementos - dunas embrionárias ou frontais, terraços marinhos holocênicos, campo de deflação eólica, vegetação de Restinga e residências.

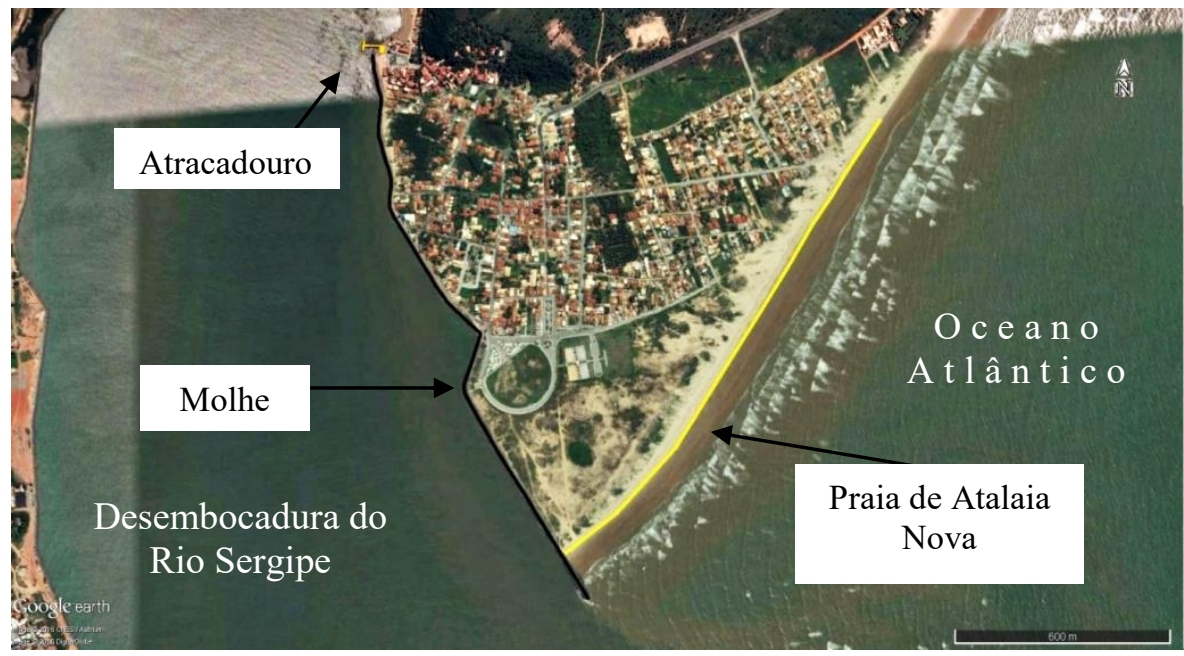

Figura 2 - Praia de Atalaia Nova e setor da Planície Costeira adjacente, Barra dos Coqueiros/SE. Fonte: GOOGLE EARTH@ (2017).

Regionalmente, a área de estudo encontra-se submetida ao clima Tropical Megatérmico Subúmido Úmido, com precipitações concentradas no período outono-inverno (ALVES, SILVA, FONTES, 2011). A temperatura média anual corresponde a $26^{\circ} \mathrm{C}$ e o índice pluviométrico anual situa-se em torno de 1590 mm, com concentração da precipitação entre os meses de março e agosto (BOMFIM et al., 2002).

Geologicamente, todo o município de Barra dos Coqueiros está representado por Coberturas Holocênicas, inseridas nas Formações Superficiais Continentais (SANTOS et al., 1998). Verificam-se nas adjacências da praia de Atalaia Nova, depósitos eólicos litorâneos atuais (QHe1) e terraços marinhos holocênicos. 
Considerando as características litológicas, Alves, Silva \& Fontes (2011, p.3) afirmam que a geomorfologia da área, "expressa o passado geológico recente, a natureza dos litotipos e a dinâmica dos processos costeiros atuantes - oceanográficos, fluviais e eólicos - em interação com o clima atual".

A paisagem de Barra dos Coqueiros é formada por feições que compõem a Planície Costeira alongada no sentido NE-SW - terraços marinhos, campos de dunas, planície fluviomarinha, campo de deflação eólica e cordões litorâneos. Sua gênese está relacionada à regressão subsequente a "Última Transgressão" ocorrida há 5.100 anos Antes do Presente (BITTENCOURT et al., 1983).

De acordo com as características apresentadas na área de estudo, o sistema praial pode ser morfologicamente setorizado, segundo o modelo de Hoefel (1998), em - Antepria; Praia Média; Face Praial, e Pós-praia -, e de acordo com os processos hidrodinâmicos, em - Zona de Arrebentação, Zona de Surfe, e Zona de Espraiamento. A praia de Atalaia Nova apresenta, predominantemente, sedimentos arenosos finos, baixa declividade, trem de ondas extenso e larga zona de espraiamento. "As praias constituem ambientes que compõem a área de transição a partir da linha de costa em direção ao oceano. São feições que encontram-se ancoradas nas Planícies Costeiras” (ALVES, 2010, p.118).

No que se refere à pedologia, o município apresenta solos de formação recente, pouco evoluído, pertencente à classe dos NEOSSOLOS QUARTZARÊNICOS Órticos, que ocorre em associação com outras classes. A praia corresponde a um tipo de ambiente formado por sedimentos quartzosos. Entretanto, na medida em que a vegetação contribuir com a adição de matéria orgânica e ocorrerem nestes solos processos pedogenéticos, os mesmos poderão evoluir para solos maduros.

$\mathrm{Na}$ Barra dos Coqueiros, a vegetação de Mangue e de Restinga, esta última composta por espécies herbáceas, arbustivas e arbóreas, está distribuída de acordo com as características dos componentes ambientais, principalmente os solos.

No que se refere à hidrografia o município está inserido na bacia do rio Sergipe (BOMFIM et al., 2002), situando-se no setor do estuário. O estuário é um ambiente marcado pela atuação de processos marinhos e fluviais. A praia de Atalaia Nova encontra-se no limite externo do estuário do rio Sergipe, marcado pelo domínio de ondas, correntes e marés. Igualmente como se verifica no litoral sergipano, predominam as mesomarés, cujo alcance varia entre $2 \mathrm{~m}$ e $4 \mathrm{~m}$, subordinadas a um regime semidiurno, com duas preamares e duas baixa-mares. A corrente de deriva litorânea propaga-se no sentido nordeste-sudoeste (NE-SW), condicionando o transporte sedimentar na costa.

De acordo com estudos de Villwock et al. (2005, p.101), nos litorais onde atuam as mesomarés, constatase a formação de "ilhas-barreira curtas e atrofiadas". Os autores supracitados denominam assim essas 
feições, por elas não terem se desenvolvido completamente em decorrência do processo de regressão marinha nos últimos 5 mil anos, que tornou inviável a manutenção do sistema ilhas-barreira. Observandose a configuração espacial da área, o município de Barra dos Coqueiros, provavelmente, corresponde a uma ilha-barreira curta e atrofiada.

\subsection{As intervenções antrópicas na Planície Costeira adjacente à Praia de Atalaia Nova}

A maior parte da população mundial vive na Zona Costeira, embora ela corresponda a apenas $15 \%$ da superfície do planeta (SOUZA et al., 2005). Atualmente, os ambientes costeiros apresentam diversos tipos de uso e possuem importância ambiental e socioeconômica.

As praias são feições deposicionais situadas na interface terra emersa e água. Encontrando-se ancoradas nas Planícies Costeiras (ALVES, 2010). De modo geral, apresentam sedimentos bem selecionados e laminados, depositados pela ação das ondas e correntes, na zona litorânea (MUEHE, 2004; SOUZA et al., 2005). As areias predominam nesses depósitos e estão sujeitas a constante remobilização pela atuação dos processos costeiros.

A Planície Costeira holocênica compõe a paisagem de Barra dos Coqueiros, correspondendo a um ambiente de formação recente. A área adjacente da praia de Atalaia Nova é composta por terraços marinhos, campos de dunas embrionárias ou frontais, corredores de deflação eólica e cordões litorâneos.

Nesse ambiente que apresenta a maior parte dos dias ensolarados, os solos são arenosos, de baixa fertilidade e estão sujeitos a apresentar teores de salinidade. Em razão dessas características há uma restrição para as atividades produtivas agrícolas, sendo a cultura do coco-da-baía (Cocos nucifera L.) dominante na área. Ela se desenvolve em associação com espécies frutíferas nativas da Restinga, principalmente a mangaba (Hancornia speciosa Gomes), (ALVES, 2010).

Segundo Bezerra, Sodré \& Brito (2012, p.1) “A mangaba é uma fruta de notada relevância para o estado de Sergipe, relevância, que levou a instituição da mangabeira como árvore símbolo do estado através do decreto $\mathrm{n}^{\circ} 12.723$ de janeiro de 1992”. Em Barra dos Coqueiros a coleta da mangaba é uma prática comum das comunidades tradicionais. Embora se verifique o extrativismo vegetal, a atividade é realizada de maneira sustentável. Desse modo, na paisagem do município, as mangabeiras ainda compõem a Restinga que coloniza as feições da Planície Costeira.

$\mathrm{Na}$ atualidade, a coleta da mangaba encontra-se ameaçada devido à crescente especulação imobiliária, pois as antigas fazendas de coco-da-baía (Cocos nucifera L.) estão sendo substituídas por condomínios de luxo de segunda residência, rede hoteleira e outras atividades de suporte ao desenvolvimento do turismo. O 
XVII Simpósio Brasileiro

de Geografia Fisica Aplicada

I Congresso Nacional

de Geografia Física
OS DESAFIOS DA GEOGRAFIA FÍSICA NA FRONTEIRA DO CONHECIMENTO

Instituto de Geociências - Unicamp

Campinas - SP

28 de Junho à 02 de Julho de 2017

crescente processo de urbanização no município tem implicado em alterações paisagísticas, ou seja, descaracterização da Zona Costeira e, consequentemente, interferido na dinâmica ambiental.

A pecuária extensiva é outra atividade encontrada na área de estudo, estando representada por pequenos rebanhos bovinos e caprinos, que se alimentam da pastagem nativa formada por espécies herbáceas da Restinga.

Nas últimas décadas na praia de Atalaia Nova são observadas mudanças nas características das feições morfológicas que compõem o setor do Pós-praia e o ambiente praial. Localmente, são constatadas a progradação da praia e a formação de um cordão de dunas frontais resultantes do bloqueio parcial dos sedimentos transportados pela corrente de deriva litorânea, após a instalação do molhe na margem esquerda da foz do rio Sergipe. Esta obra de engenharia foi planejada e executada visando estabilizar a foz do rio referido, buscando conter os processos erosivos que ameaçavam o projeto urbanístico da cidade de Aracaju, situada na margem direita.

De acordo com Mello e Ponçano (1998, p.459), “os molhes são estruturas que avançam da praia ao mar", e "podem ser construídos de modo simples, com pedras ou sintéticos, constituindo um tipo de enrocamento, ou, de modo mais complicado, com núcleo, carapaça e enrocamento", tendo objetivo principal de "interferir na deriva litorânea, causando acumulação de areias, ou retardando a erosão praial". No povoado Atalaia Nova o molhe foi constituído de modo simples, por meio do enrocamento de rochas (Figura 3).

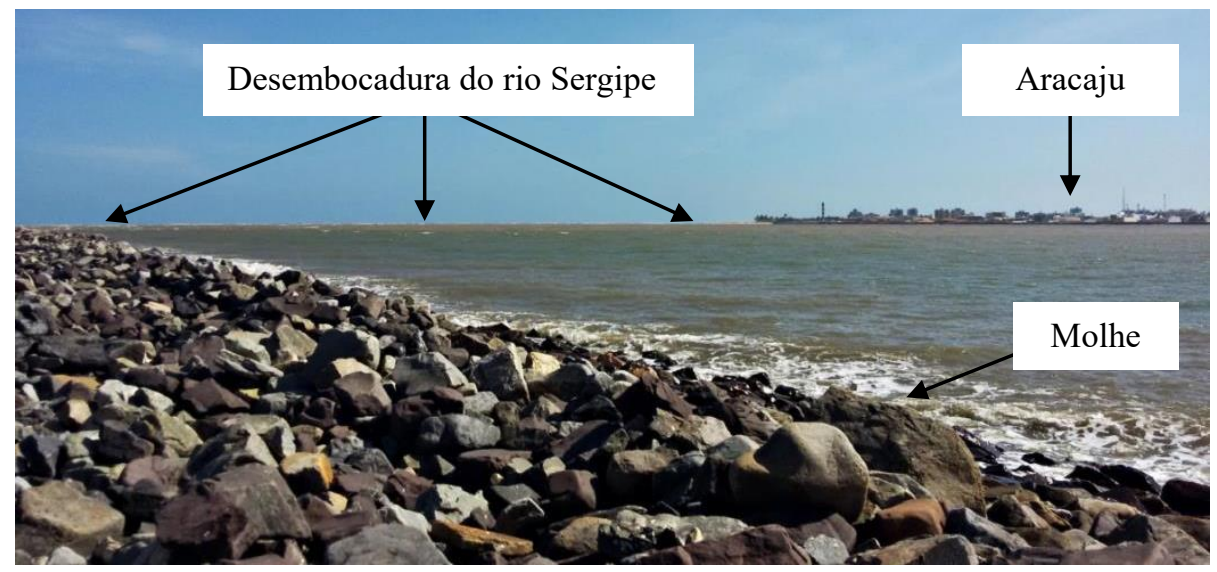

Figura 3 - Visão de parte do molhe, margem esquerda da foz do rio Sergipe, povoado de Atalaia Nova, Barra dos Coqueiros. Em segundo plano, situação do bairro Coroa do Meio, Aracaju/SE.

Inicialmente, em 1990, o projeto da construção do molhe na praia de Atalaia Nova, definia um comprimento de $1.200 \mathrm{~m}$ em “direção ao mar e uma proteção na margem do rio, com 950m de extensão, 
XVII Simpósio Brasileiro

de Geografia Fisica Aplicada

I Congresso Nacional

de Geografia Física
OS DESAFIOS DA GEOGRAFIA FÍSICA NA FRONTEIRA DO CONHECIMENTO

Instituto de Geociências - Unicamp

Campinas - SP

28 de Junho à 02 de Julho de 2017

desde o início ou enraizamento do molhe até o terminal hidroviário da Atalaia Nova". Estava prevista também a estruturação de uma proteção frontal na margem direita, no bairro Coroa do Meio, em Aracaju, “com $2.800 \mathrm{~m}$ de extensão [...]", além da "[...] construção de vários espigões para reforçar a estrutura da obra anterior e protegê-la da ação erosiva das correntes" (WANDERLEY, 2006, p.186).

Embora o cronograma do projeto ressaltasse que, tanto o molhe da praia de Atalaia Nova, "quanto a proteção marginal da Coroa do Meio" deveriam ser fixados concomitantemente, houve descumprimento do cronograma e interrupções durante a execução das obras (WANDERLEY, 2006, p.186). Como consequência, os processos costeiros foram alterados, proporcionando a formação de bancos arenosos próximos à linha de costa, estreitamento a desembocadura do rio com migração do talvegue para a margem direita do rio Sergipe e, consequentemente, intensificação da erosão na Coroa do Meio, enquanto em Barra dos Coqueiros, na praia de Atalaia Nova, verificou-se a progradação da linha de costa. Estas ocorrências corroboram com a análise de Mello e Ponçano (1998) sobre o barramento da corrente de deriva litorânea por estruturas de obras de engenharia. Atualmente, o molhe possui aproximadamente, $1.700 \mathrm{~m}$ de extensão (Figura 2), a partir da praia de Atalaia Nova, sentido de montante do rio Sergipe.

No setor de abrangência da área de estudo, na praia propriamente dita, os moradores locais costumam extrair da Face Praial sedimentos arenosos, que utilizam como material de aterro nos terrenos de suas residências (Figura 4). Esta ação contribui para o déficit no balanço sedimentar do sistema praial.

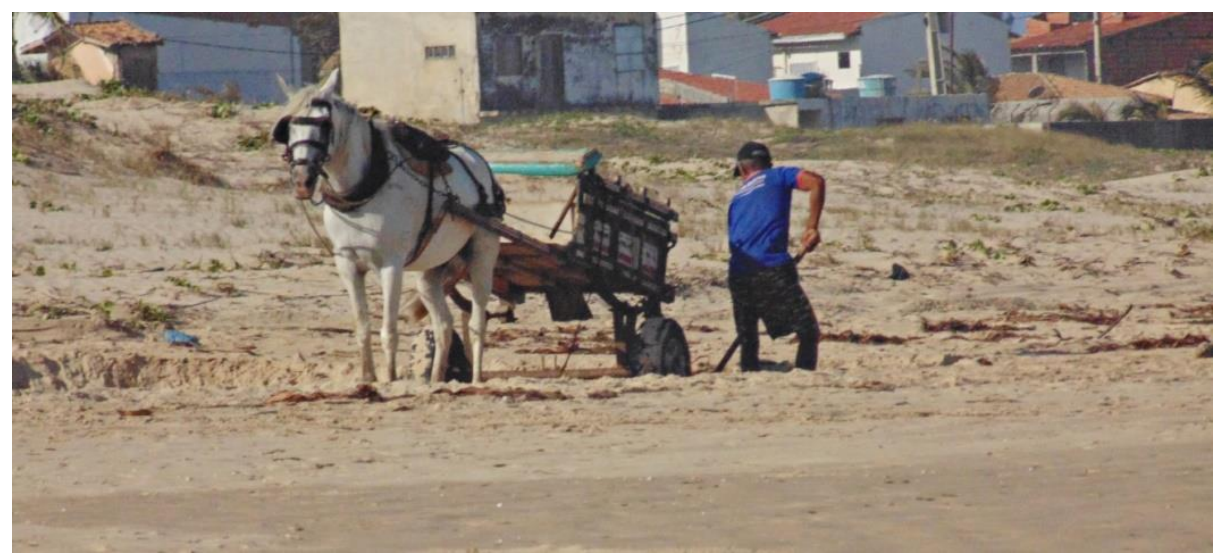

Figura 4 - Retirada de areia na Face Praial. Praia de Atalaia Nova - Barra dos Coqueiros/SE. Fonte: SANTO, Y. A. A. E. (2016)

\section{Resultados e Discussões}

Existem trabalhos publicados sobre a área deste estudo, abordando inclusive a progradação condicionada pelo molhe construído para estabilizar a foz do rio Sergipe (WANDERLEY, 2006; BITTENCOURT, 


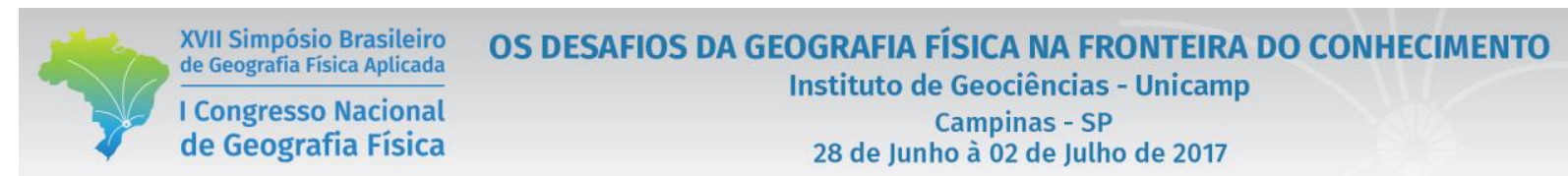

OLIVEIRA, DOMINGUEZ, 2006; SANTOS et al., 2006; RODRIGUES, 2008; SANTANA, 2008; CEHOP, 2009; ALVES, 2010).

Rodrigues (2008), em seu estudo, enfatizou a evolução da linha de costa na desembocadura do rio Sergipe. Numa análise em médio prazo, foi possível verificar que na praia de Atalaia Nova, entre os anos de 19552003, ocorreram processos erosivos, porém os de progradação foram mais intensos, principalmente a partir da instalação do molhe em 1990.

Considerando-se as análises procedidas dos produtos cartográficos e de imagens de satélites dos anos de 2004, 2009, 2011 e 2017 por meio Google Earth Pro®, evidenciou-se o dinamismo da linha de costa na praia de Atalaia Nova e setor da foz do rio Sergipe, conforme representado nas figuras 5A, 5B, 5C e 5D.
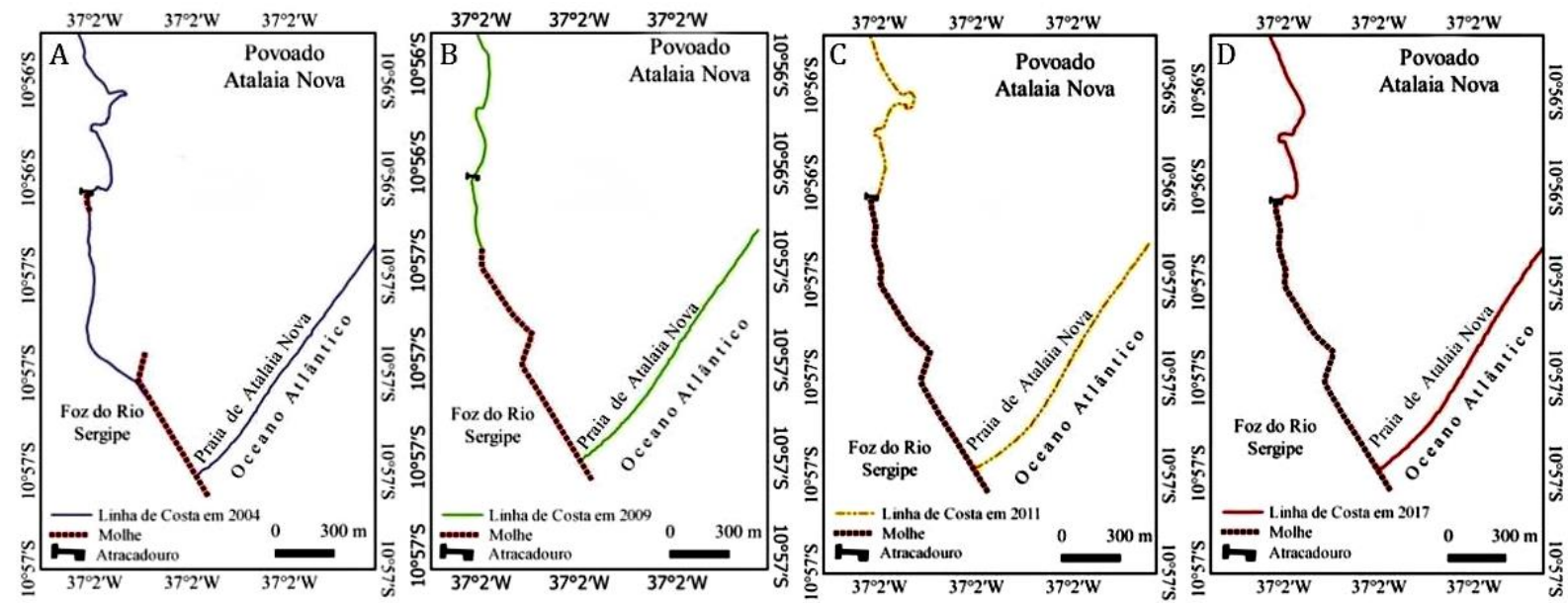

Figura 5 - Representação do molhe e da variação da linha de costa, nos anos de 2004(A), 2009(B), 2011(C) e 2017(D), Praia de Atalaia de Atalaia Nova, Barra dos Coqueiros/SE.

Fonte: Dados brutos do Google Earth Pro.

De acordo com a análise comparativa das imagens interpretadas, constatou-se que em janeiro de 2004 (Figura 5A), o molhe apresentava extensão de aproximadamente $850 \mathrm{~m}$. A intensificação dos processos erosivos fluviais e marinhos, resultou na necessidade da ampliação do molhe, que em dezembro de 2009 (Figura 5B) possuía cerca de $1.365 \mathrm{~m}$, ou seja, 500 metros a mais em relação a 2004. Desde 2011 até o presente momento (Figuras 5C e 5D) o molhe conserva uma extensão em torno de $1.700 \mathrm{~m}$. Diante dessa análise, é possível afirmar que a ampliação do molhe foi condicionada pelo avanço da erosão costeira que atua a partir da praia de Atalaia Nova, sentido de montante do rio Sergipe, como consequência das intervenções antrópicas.

Conforme Costa, Santos \& Silva (2009), em razão da construção do molhe em formato de "L", ocorreu uma progradação no setor da margem esquerda do rio Sergipe, formando uma pequena praia fluvial. Entre 2004 e 2009 está área de aproximadamente $0,075 \mathrm{~km}^{2}$, foi erodida (Figura 6). Segundo os autores, as ondas 


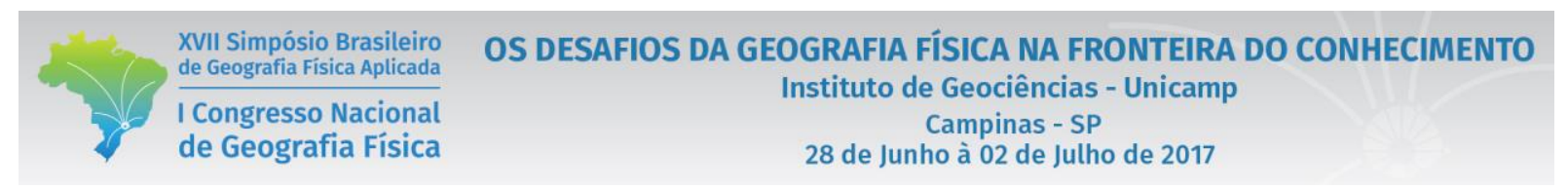

que atingiam o molhe, sofriam difração, e a mudança na direção da sua propagação favoreceu esta erosão. Em 2011 o molhe já alcançava o atracadouro, tendo sido ampliado cerca de 335m, em relação a 2009.

As constatações efetuadas revelam a dinamicidade atuante na desembocadura fluvial do rio Sergipe, resultante da interação dos processos fluviais e marinhos, intensificada pela interferência antrópica. A figura 6 mostra a variabilidade da linha de costa da praia de Atalaia Nova, representando setores em erosão e outros em progradação, no recorte temporal analisado.

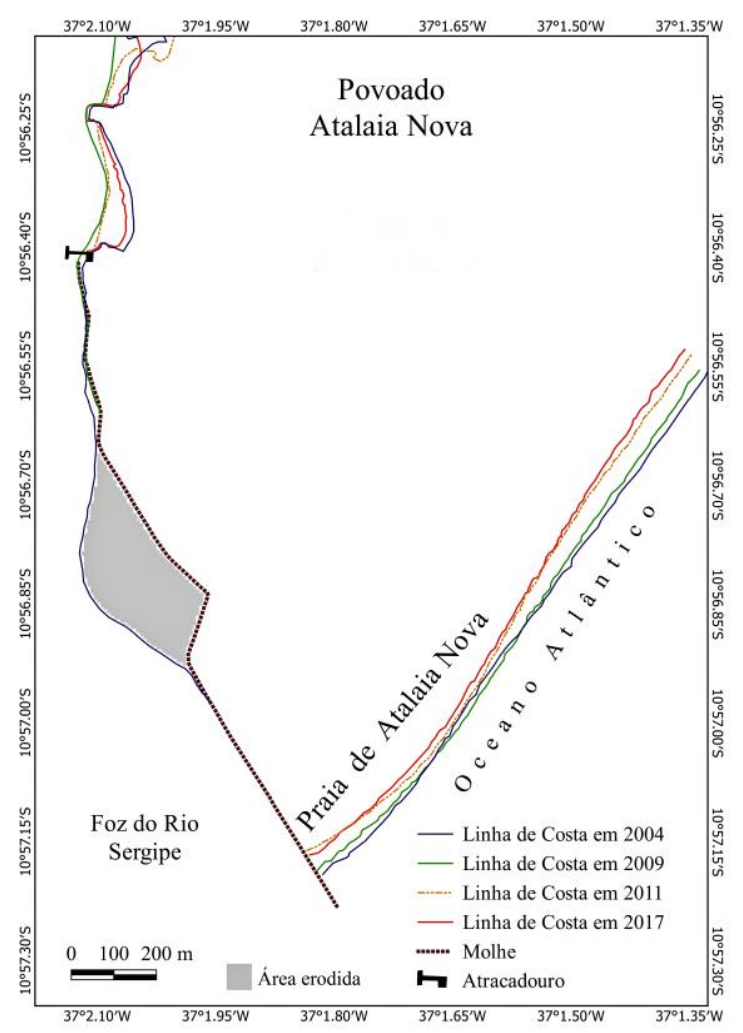

Figura 6 - Síntese da evolução da linha de costa, no período de 2004-2017, Praia de Atalaia Nova, Barra dos Coqueiros/SE.

Fonte: Dados brutos do Google Earth Pro.

Em campo foi observado que na margem esquerda do rio Sergipe os blocos rochosos que formam o molhe são deslocados constantemente em razão do solapamento basal pelo impacto das ondas. Por sua vez, na Face Praial foram identificados indicadores de erosão como - escarpa erosiva nas dunas frontais e terraços marinhos, e obra de proteção costeira (molhe). Da mesma forma, constatam-se processos erosivos e progradacionais que se alternam na margem esquerda do rio Sergipe, após o atracadouro situado no povoado de Atalaia Nova, colocando em risco as residências nas proximidades. 


\section{Considerações Finais}

A metodologia e os procedimentos aplicados permitiram alcançar o objetivo do estudo realizado. Os produtos cartográficos finais demostram a variabilidade da linha de costa na margem esquerda do rio Sergipe, bem como a ampliação do molhe devido o avanço da erosão.

As análises executadas revelaram que os processos oceanográficos, fluviais e eólicos atuantes na Planície Costeira resultaram na elaboração de terraços marinhos, cordões litorâneos e dunas frontais, no setor de abrangência da praia. Entretanto, os tipos de uso e intervenções - construção de molhe na desembocadura do rio Sergipe, extração de areia e a especulação imobiliária - vêm concorrendo para a alteração dessas morfologias, descaracterizando a paisagem. Desse modo, são indispensáveis estudos mais apurados sobre a dinâmica desse ambiente, a fim de que se possam ter compreensão dos processos atuantes.

\section{Agradecimentos}

O presente trabalho foi realizado com apoio da COPES/POSGRAP/UFS.

\section{REFERÊNCIAS}

ALVES, N. M. S. Análise geoambiental e socioeconômica dos municípios costeiros do litoral norte do estado de Sergipe - diagnóstico como subsidio ao ordenamento e gestão do território. 2010. 348 f. Tese (Doutorado em Geografia) - Núcleo de Pós-Graduação em Geografia, Pró-Reitoria de Pós-Graduação e Pesquisa, Universidade Federal de Sergipe, São Cristóvão.

ALVES, N.M.S.; SILVA, D.B.; FONTES, A.L. XIII Congresso da Associação Brasileira de Estudos do Quaternário e III Encontro do Quaternário Sulamericano - O Quaternário Sul Americano: Desafios e Perspectivas, 2011, Armação dos Búzios - Rio de Janeiro. Anais eletrônicos... Armação dos Búzios - Rio de Janeiro: ABEQUA, 2011. ISSN: 2318-0986. Disponível em : $<$ http://www.abequa.org.br/trabalhos/BARRA_DOS_COQUEIROS.pdf $>$. Acesso em 13 de dezembro de 2016.

BERTRAND, G. Paisagem e geografia física global: esboço metodológico. R. RA' E GA, Curitiba, n. 8, p. 141-152, 2004. Editora UFPR.

BEZERRA, M. F. L.; SODRÉ, M. L. S.; BRITO, J. V. S. Catadoras de mangaba de Barra dos Coqueiros: Mães e filhas do fruto dessa terra. In: SEMINÁRIO SOBRE ALIMENENTOS E MANIFESTAÇÕES CULTURAIS TRADICIONAIS, 1, 2012, São Cristóvão - Sergipe. Anais eletrônicos... São Cristóvão - Sergipe: GRUPAM, 2012. Disponível em: http://m.grupam.net/anais-do-i-seminario-sobre-alimentos-e-manifesta\%c3\%a7\%c3\%b5es-culturaistradicionais/. Acesso em: 01/02/2017.

BITTENCOURT, A.C.S.P.; MARTIN, L.; DOMINGUEZ, J.M.L.; FERREIRA, Y. de A. 1983. Evolução paleogeográfica quaternária da costa do estado de Sergipe e da costa sul do estado de Alagoas. Revista Brasileira de Geociências, v.13, p. 93-97.

BITTENCOURT, Abílio ; OLIVEIRA, Marta Becker de ; DOMINGUEZ, José Maria Landim . Erosão e Progradação do Litoral Brasileiro- Sergipe. In: Dieter Muehe. (Org.). Erosão e Progradação do Litoral Brasileiro. 2ed.Brasília: Ministério do Meio Ambiente, 2006, v. , p. 213-218.

BOMFIM, L.F.C.; COSTA, I.V.G.da; BENVENUTI, S.M.P. Projeto Cadastro da Infra-Estrutura Hídrica do Nordeste: Estado de Sergipe. Diagnóstico do Município de Barra dos Coqueiros. Aracaju: CPRM, p.12, 2002. 
BRASIL. Ministério das Minas e Energia. Projeto RADAMBRASIL: folha SC.24/25 Aracaju/Recife: geologia, geomorfologia, pedologia, vegetação, uso potencial da terra. Rio de Janeiro, 1983. 851 p. (Levantamento de Recursos Naturais,30

CEHOP. Companhia Estadual de Habitação e Obras Públicas; Terra Viva Consultoria em Meio Ambiente e Geologia. RIMA - Relatório de Impacto Ambiental. Projeto de Urbanização da Orla de Atalaia Nova trechos V, VI, VII e VIII.. Aracaju, 2009. Relatório.

COSTA, J. J.; SANTOS, M. A. ; SILVA, R. R. S. . Erosão Costeira: Estudo de Caso nas Praias de Atalaia Nova e Coroa do Meio - Sergipe/BRASIL. In: 12 Encuentro de Geógrafos de América Latina, 2009, Montevideo. Anais..... Montevideo: Editora do Egal, 2009. v. 7. p. 01-15.

HOEFEL, F. G. Morfodinâmica de Praias Arenosas Oceânicas: uma revisão bibliográfica. Itajaí: Editora da Univale, 1998.

IBGE. Cidades. Sergipe: Barra dos Coqueiros. $2016 . \quad$ Disponível em: <http://cidades.ibge.gov.br/xtras/perfil.php?lang=\&codmun=280060\&search=\|infogr\%E1ficos:-informa\%E7\%F5escompletas >. Acesso em 15 de dezembro de 2016.

MEllo, J. R. C.; PONÇANO, W. L.. Obras Marítimas. In: OliVEIRA, A. M. S.; BRITO, S. N. A. de. (Org.). Geologia de Engenharia. 1ed. São Paulo: ABGE - Associação Brasileira de Geologia de Engenharia, 1998, v. 1, p. 457-467.

MENDONÇA, J.U. de; SILVA, M.L.M.C (Org.). Sergipe Panorâmico. 2. Ed. Aracaju: UNIT, 2009, p.79-84.

MUEHE, D. Definição de limites e tipologias da orla sob os aspectos morfodinâmico e evolutivo. In: MORAES, C. R de; ZAMBONI, A. (org.). Projeto Orla subsídios para um projeto de gestão, 2004, pp.13-32, Ministério do Meio Ambiente (MMA) e Ministério do Planejamento, Orçamento e Gestão (MPO), Brasília, DF, Brasil. Disponível em: $<$ http://www.mma.gov.br/estruturas/orla/_arquivos/11_04122008110506.pdf >. Acessado em 09/11/2016.

RODRIGUES, T. K. Análise das mudanças da linha de costa das principais desembocaduras do estado de Sergipe, com ênfase no rio Sergipe. 2008. 91 f. Dissertação (Mestrado em Geologia) - Curso de Pós-Graduação em Geologia, Instituto de Geociências, Universidade Federal da Bahia, Salvador.

SANTANA, L. B. de. Análise Geoambiental dos municípios costeiros de Barra dos Coqueiros e Pirambu (SE). 2008. 111 f. Dissertação (Mestrado em Geografia) - Núcleo de Pós-Graduação em Geografia, Pró-Reitoria de PósGraduação e Pesquisa, Universidade Federal de Sergipe, São Cristóvão.

SANTOS, M. A. ; FONTES, A. L. ; SANTOS, C. O. dos ; COSTA, J. J. . Abordagem Preliminar dos Condicionantes Geomorfológicos da Zona Costeira do Município de Itaporanga d'Ajuda - Sergipe / Brasil: contribuições à gestão ambiental. In: VII Simpósio Nacional de Geomorfologia - SINAGEO - II Encontro Latino-Americano de Geomorfologia, 2008, Belo Horizonte - MG. Anais.... Belo Horizonte: Editora do UFMG, 2008. p. 1-10.

SANTOS, P. P.; VILAR, J. W. C. A segunda residência no litoral de Sergipe (Brasil): entre os "velhos" e os "novos" territórios. In: CONGRESO IBEROAMERICANO DE ESTUDIOS TERRITORIALES Y AMBIENTALES, $6,2014$. Anais eletrônicos... São Paulo: USP, 2014. Disponível em: http://6cieta.org/anais/eixo1/. Acesso em 06/06/2016.

SANTOS, R. A. dos, org. et al. Programa Levantamentos Geológicos Básicos do Brasil -PLGB. Geologia e recursos minerais do Estado de Sergipe. Escala 1:250.000. Texto explicativo do Mapa geológico do Estado de Sergipe. SANTOS, R. A. dos; MARTINS, A. A. M.; NEVES, J. P. da; LEAL, R. A. (Orgs.). - Brasília: CPRM/DIEDIG/DEPAT; CODISE, 1998.

SOUZA, C.R. de G; SOUZA FILHO, P.W.M. e; ESTEVES, LS.; VITAL, H; DILLENBURG, S.R; PATCHINEELAM, S.M.; ADDAD, J.E. Praias arenosas e erosão costeira. In: SOUZA et al. Quaternário do Brasil. Ribeirão Preto: Holos, Editora, 2005.

VILLWOCK, J. A. LESSA, G. C. SUGIO, K. ÂNGULO, R. J. DILLENBURG, S. R. Geologia e geomorfologia de regiões costeiras. In: SOUZA et al. Quaternário do Brasil. Ribeirão Preto: Holos, Editora, 2005.

WANDERLEY, L.L. Paisagem da janela: Esse nosso Inconstante Rio Sergipe e a Evolução de sua Foz. In: Alves J.P.H. (ed.) Rio Sergipe: importância, vulnerabilidade e preservação. São Cristóvão: Editora UFS, 2006, p.: 165194.

DOI - 10.20396/sbgfa.v1i2017.1988 - ISBN 978-85-85369-16-3 